\title{
Long-term durability tests of andesite aggregates from Hungary
}

\author{
Balázs Czinder*, Ákos Török \\ Department of Engineering Geology and Geotechnics, Budapest University of Technology and Economics, \\ Budapest, Hungary
}

Received: August 2, 2017; revised manuscript received: October 4, 2017; accepted: October 5, 2017

The Micro-Deval test method is used for testing of aggregate durability. The present paper focuses on two Hungarian andesites obtained from the quarries of Recsk (Mátra Mountains, Hungary) and of Nógrádkövesd (Cserhát Mountains, Hungary). The aim of this study is to find a simple test method based on the original Micro-Deval test method to assess the long-term durability of aggregates. An additional part of the research was to develop suitable mathematical models that can describe the behavior of the andesite aggregates under continuous abrasive impact. The relevant standard (EN 1097-1:2012) recommends 12,000 rotations to determine the Micro-Deval coefficient required for classification of the aggregates. Within the framework of this research, a modified Micro-Deval test was applied: the number of rotations was increased in several steps and the degree of abrasion was measured afterwards. Regression analyses were used to outline mathematical forms which characterize the dependence between the number of rotations and the degree of abrasion. According to the results, the long-term Micro-Deval tests significantly modify the assessed durability and thus provide information on the long-term abrasive impact. The degree of change depends on the studied material: the ratio of the long-term Micro-Deval coefficients of the two studied andesite types is larger than 3. The regression analyses of the measured Micro-Deval coefficients revealed that quadratic curves are suitable to describe these tendencies for both andesite aggregates.

Keywords: andesite, aggregate, durability, long-term properties, regression analysis

*Corresponding author: Balázs Czinder; Department of Engineering Geology and Geotechnics, Budapest University of Technology and Economics, Müegyetem rkp. 3., H-1111 Budapest, Hungary E-mail: czinder.balazs@epito.bme.hu

This is an open-access article distributed under the terms of the Creative Commons Attribution License, which permits unrestricted use, distribution, and reproduction in any medium for non-commercial purposes, provided the original author and source are credited. 


\section{Introduction}

Igneous rocks are frequently used as aggregate in Hungary. Volcanic rocks such as basalt and andesite are the most common types found in Hungary and utilized in the construction industry as aggregates (Gálos and Kárpáti 2007; Török 2007), whereas sedimentary rocks in Hungary are mostly used as building or decorative stones (Török et al. 2004; Török 2007). The favorable properties of andesite (high uniaxial compressive strength and resistance to abrasion) make it suitable for use in road and railway construction in the form of aggregate or armor stone and as blocks in hydraulic engineering.

Several test methods exist to determine the aggregate properties of rock materials: the polished stone value test (Đokić et al. 2015), the slake durability test (Miščević and Vlastelica 2011), the Nordic test (Krutilová and Přikryl 2017), aggregate crashing and aggregate impact value tests (Palassi and Danesh 2016), and Washington degradation tests (Liu et al. 2017). The most common methods, such as Los Angeles (LA) and Micro-Deval (MDE) tests, usually focus on the determination of durability (Erichsen et al. 2011). The LA and MDE test results are taken as the basis of the different classification systems (Czinder and Török 2015; Palassi and Danesh 2016).

Long-term durability is also important for the description of the behavior of the various rocks undergoing continuous abrasive impact. Erichsen (2015) tested the longterm durability of jasper and greenstone by LA tests; the samples were subjected to different numbers of rotations. The alteration of the slake durability index (Id), according to increasing number of test cycles of Dalmatian (Croatia) marls (Miščević and Vlastelica 2011) and clay-bearing rocks from Turkey (Gökceoğlu et al. 2000), was also analyzed.

Relationships could be found between rock mechanical parameters and aggregate properties. According to Rigopoulos et al. (2013), the MDE test results correlate with uniaxial compressive strength in the case of ophiolite complexes from Greece. A dependence has been found between the polished stone value and the Nordic abrasion value of various igneous rocks (Krutilová and Přikryl 2017). Schmidt hammer rebound values and point load tests were correlated with LA values (Kahraman and Gunaydin 2007). Recently, Török (2015) revealed the relationship between the LA and MDE test results of Hungarian andesite and basalt, whereas Czinder and Török (2015) compared the ultrasonic pulse velocity, the strength parameters, and aggregate properties of the Gyöngyössolymos andesite (Hungary).

The present paper focuses on aggregate properties and does not provide a detailed petrographic description of the studied andesite. However, it is important to note that mineralogical properties of the igneous rocks influence the mechanical and aggregate properties (Tugrul and Zarif 1999; Prrikryl 2001; Yilmaz et al. 2011). The uniaxial compressive strength is affected by the relative abundance of the phenocrysts in andesitic rocks (Ündül 2016). The mineral composition of the rocks also has a great influence on aggregate durability (Pang et al. 2010); the average crystal size and the Mohs hardness correlate with the Micro-Deval values (Wang et al. 2015). 
The current research takes a different approach. It focuses on the description of long-term behavior of aggregates using extended abrasion. The standardized MicroDeval test requires 12,000 rotations, whereas in this paper the andesite aggregates were subjected to up to 10 times more rotations $(120,000$, respectively) to assess the behavior of wear durability. This intense wear and the detection of material loss allowed us to apply suitable mathematical models to describe the material loss.

\section{Materials}

Andesites from two quarries in the northern part of Hungary were used to prepare aggregate samples for the laboratory tests (Fig. 1). The andesite from Nógrádkövesd (Cserhát Mountains, Hungary) was formed during the Miocene volcanism and the andesite from Recsk (Mátra Mountains, Hungary) was formed in the Eocene. Both rock materials show quite homogenous fabrics.

The rock mechanical parameters of the studied materials were determined previously (Table 1; Czinder and Török 2015, 2017).

\section{Methods}

The durability of the studied andesites was described by Micro-Deval tests (the relevant standard is EN 1097-1:2012). The aggregate samples were made from two fractions representing two ranges: $150 \mathrm{~g}$ of $10.0-11.2 \mathrm{~mm}$ and $350 \mathrm{~g}$ of $11.2-14.0 \mathrm{~mm}$ in size, respectively. The aggregate samples were tested in steel drums (Fig. 2). The abrasive impact was provided by 5,000 $\mathrm{g}$ of steel balls and 2,500 $\mathrm{ml}$ of water in the

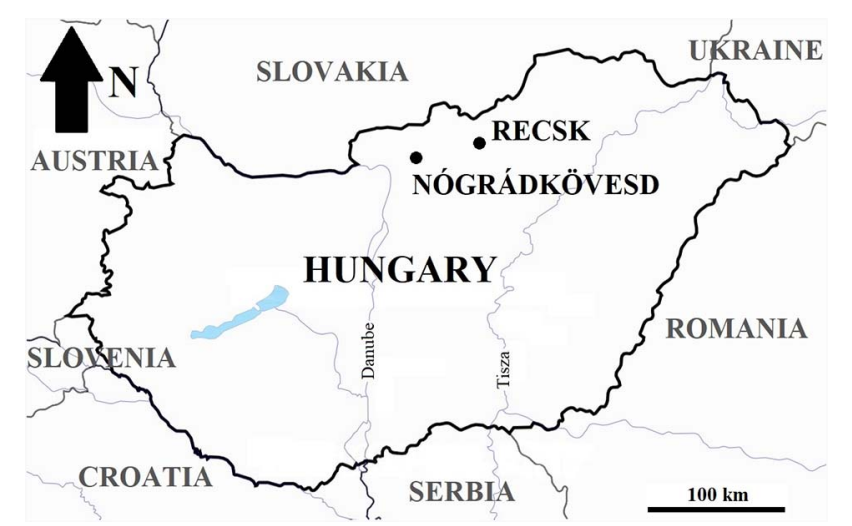

Fig. 1

Location of the studied quarries in Hungary 
Table 1

The mean rock mechanical parameters of the studied andesites

\begin{tabular}{llll}
\hline \multirow{2}{*}{$\begin{array}{l}\text { Rock mechanical } \\
\text { parameters }\end{array}$} & \multicolumn{1}{c}{ Conditions } & Recsk & Nógrádkövesd \\
\hline $\begin{array}{l}\text { Uniaxial compressive } \\
\text { strength }(\mathrm{MPa})\end{array}$ & Air-dry & 270.8 & 85.4 \\
\cline { 2 - 4 } & Water saturated & 265.7 & 76.0 \\
\cline { 2 - 4 } & Freeze-thaw subjected & 244.8 & 78.0 \\
\hline \multirow{2}{*}{$\begin{array}{c}\text { Modulus of elasticity } \\
(\mathrm{GPa})\end{array}$} & Air-dry & 48.7 & 22.5 \\
\cline { 2 - 4 } & Water saturated & 48.2 & 28.8 \\
\cline { 2 - 4 } & Freeze-thaw subjected & 47.0 & 23.8 \\
\hline \multirow{2}{*}{$\begin{array}{l}\text { Tensile strength }(\mathrm{MPa}) \\
\end{array}$} & Air-dry & 9.8 & 7.9 \\
\cline { 2 - 4 } & Water saturated & 6.4 & 6.4 \\
\cline { 2 - 4 } & Freeze-thaw subjected & 8.3 & 5.8 \\
\hline
\end{tabular}

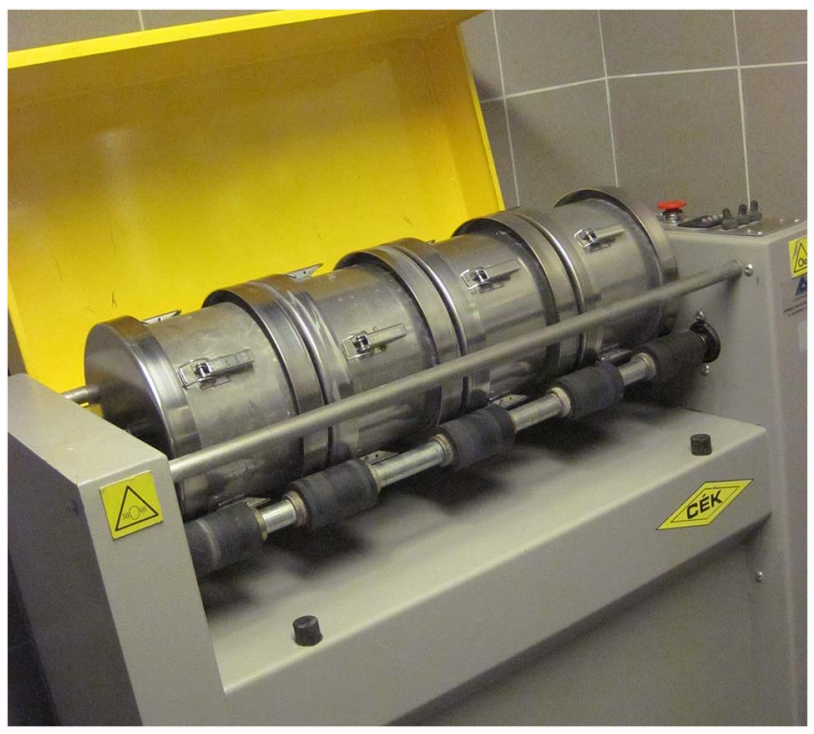

Fig. 2

The Micro-Deval test equipment with four drums

drums which are rotated during the tests (100 rotations per minute). According to the relevant EN standard, the result of the Micro-Deval test is the Micro-Deval coefficient $\left(M_{D E}\right)$ which is the ratio of the abraded mass after 12,000 rotations and the original 
mass of the sample. In the evaluation, a smaller Micro-Deval coefficient indicates more favorable aggregate properties. The Micro-Deval tests were made in pairs; thus, two test results were obtained for each set of experiments.

To determine the long-term aggregate properties of the samples, additional rotations were made with increments of 12,000 rotations. Two series of measurements were made. In the first set (called test 'A'), the aggregate samples were washed, dried, and measured after the total number of rotations. For test ' $A$ ', different aggregate samples were needed for each experimental setting. The number of rotations was increased by 12,000 rotations to 120,000 and an additional stage (6,000 rotations) was also investigated. The other series of measurements (called test ' $\mathrm{B}$ ') describes the tests where MDE values were measured after each 12,000 rotations, until reaching 120,000 rotations.

The long-term Micro-Deval coefficients (MDE) of both test types were calculated (similarly to the standardized Micro-Deval coefficient) as the ratio of the abraded and the original mass measured after the increased number of rotations. According to the results of test ' $\mathrm{B}$ ', a modified or relative coefficient $\left(M D E^{\prime}\right)$ was also calculated at every stage of the increasing number of rotations:

$$
M D E_{n}^{\prime}=\frac{m_{n-1}-m_{n}}{m_{n-1}} \times 100(\%)
$$

where $m_{n}$ is the mass of the aggregate and $M D E^{\prime}{ }_{n}$ is the relative Micro-Deval value at the $n$th stage of the increasing number of rotations. The measurements of test ' $\mathrm{B}$ ' required only two aggregate samples, i.e., the tests were made on the same pair of samples throughout.

Regression analyses were used to find suitable statistical models which can describe the correlation between the number of rotations and the Micro-Deval coefficients. The adequacy of the models was described by the Pearson's coefficient of correlation $\left(R^{2}\right)$.

The notations of the different Micro-Deval values:

$-M_{D E}$ : the Micro-Deval value determined after 12,000 rotations according to the relevant EN standard;

- MDE: the long-term Micro-Deval value;

$-M D E_{A}$ or $M D E_{B}$ : the long-term Micro-Deval values determined after test ' $A$ ' or ' $B$ ';

- $M D E^{\prime}$ : modified or relative Micro-Deval value.

\section{Results and discussion}

The long-term Micro-Deval tests caused significant loss in mass of the studied andesite aggregates (Table 2). The number of rotations was increased to 120,000 in 11 steps. The grains became smaller and more subspherical with the increasing number of rotations (Fig. 3). 
Table 2

The long-term Micro-Deval coefficients of the studied andesites

\begin{tabular}{lcccc}
\hline & \multicolumn{2}{c}{$M D E_{A}$ value } & \multicolumn{2}{c}{$M D E_{B}$ value } \\
\hline Number of rotations & \multicolumn{2}{c}{ Recsk } & \multicolumn{2}{c}{ Nógrádkövesd } \\
\hline 6,000 & 3.3 & - & 8.7 & - \\
\hline 12,000 & 4.9 & 4.9 & 15.6 & 14.6 \\
\hline 60,000 & 12.2 & 11.7 & 49.7 & 44.6 \\
\hline 120,000 & 18.9 & 17.1 & 70.6 & 66.1 \\
\hline
\end{tabular}

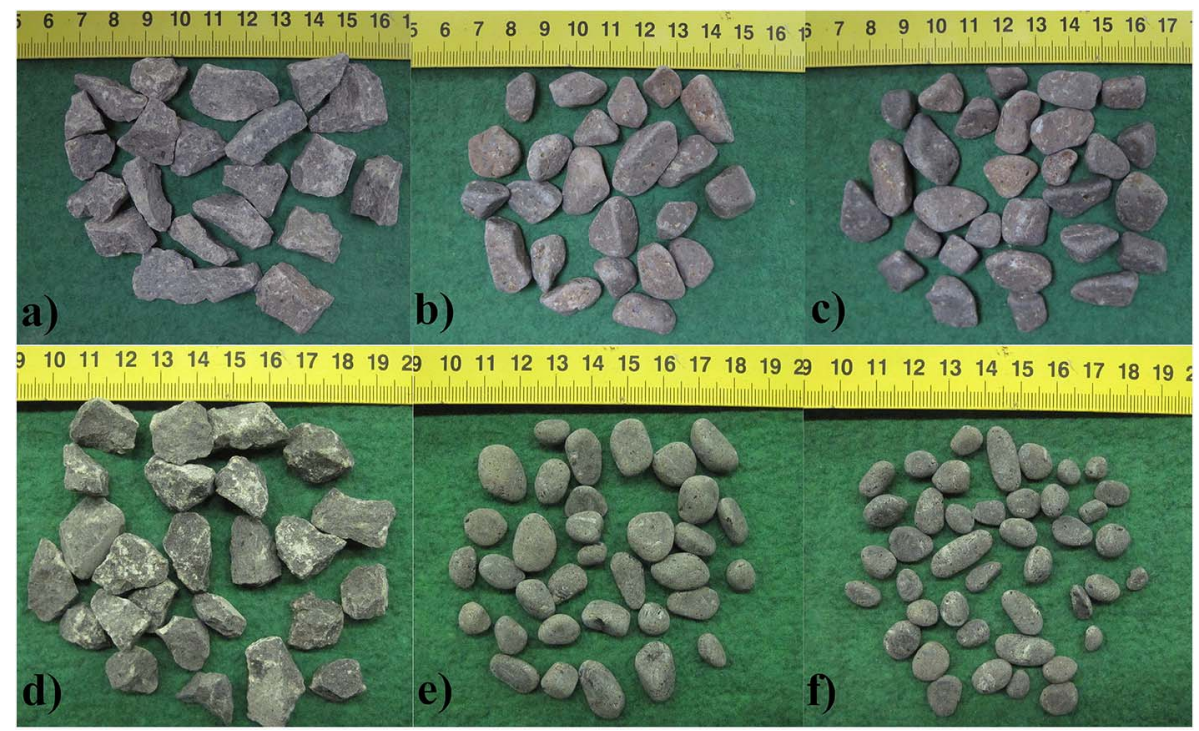

Fig. 3

The grains after 0 (a, d), after 60,000 (b, e), and 120,000 rotations (c, f), respectively. Top row displays andesite from Recsk (images: a, b, c); bottom row shows andesite from Nógrádkövesd: (images: d, e, f)

The test results of test 'A' fit well to quadratic curves (Fig. 4); the coefficient of correlation reached 0.9 for both andesites. The functions of the fitted curves do not contain any constant member, since in the mathematical representation, the initial phase (when the number of rotations and the MDE were 0 ) was considered as a fixed point. When a constant member is kept in the functions, the Pearson's coefficient is even slightly higher: 0.998 and 0.98 for the andesites from Nógrádkövesd and Recsk, respectively. The MDE test results that represent the standardized 12,000 rotations are 


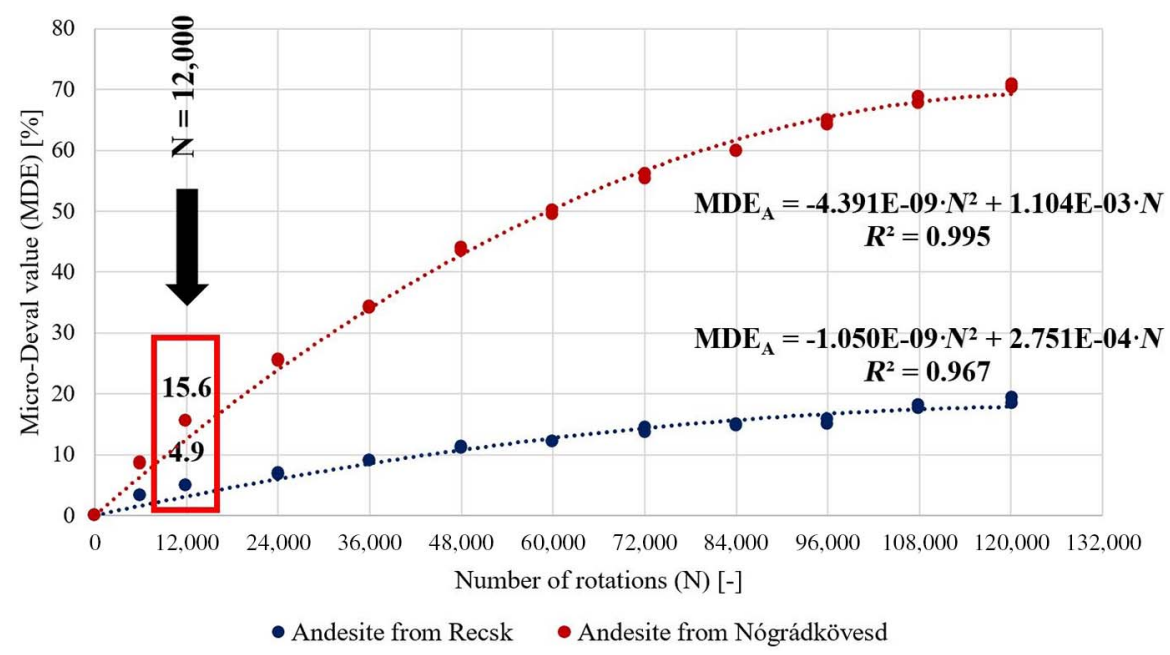

Fig. 4

The MDE values according to the number of rotations, test 'A' (see explanation of test ' $\mathrm{A}$ ' in the text)

highlighted by a red rectangle (Fig. 4). It is clear that long-term abrasive impact reduces the durability of andesite aggregates and decreases the MDE values, similarly to previous findings on greenstone (Erichsen 2015). These results suggest that the standardized Micro-Deval test provides information on aggregate durability but does not allow precisely assessing the long-term behavior of andesites (Fig. 4). In other words, 12,000 rotations do not necessarily represent the material durability.

The comparisons of the test results of ' $A$ ' and ' $B$ ' also brought new insights. The differences between test ' $A$ ' and test ' $B$ ' are shown in Figs 5 and 6 for the andesites from Recsk and Nógrádkövesd, respectively. The Micro-Deval coefficients obtained in test ' $\mathrm{B}$ ' $\left(M D E_{B}\right)$ are smaller at higher number of rotations. This is caused by the finegrained mass of the abraded aggregates which increased the abrasive impact during test 'A' (the differences between $M D E_{A}, M D E_{B}$, and $M D E^{\prime}$ values at 12,000 rotations are negligible, so the data points uncover each other. Both figures contain data points of each series of measurements).

The mass reductions of the aggregate samples from the different quarries show significant differences: the MDE value of the andesite from Recsk is 17.1 (Fig. 5), whereas the andesite from Nógrádkövesd provided $\mathrm{MDE}=66.1$ after 120,000 rotations (Fig. 6).

In both cases, the plots of the modified $M D E^{\prime}$ values follow decreasing trends. The reason is that the material of the aggregates did not change during the long-term tests, but the shape of the grains became smaller and more subspherical by the abrasion of the vertices and the edges of the grains. However, although the quadratic model provides satisfying $R^{2}$ values for $M D E^{\prime}$, it was not feasibly to apply it: at higher 


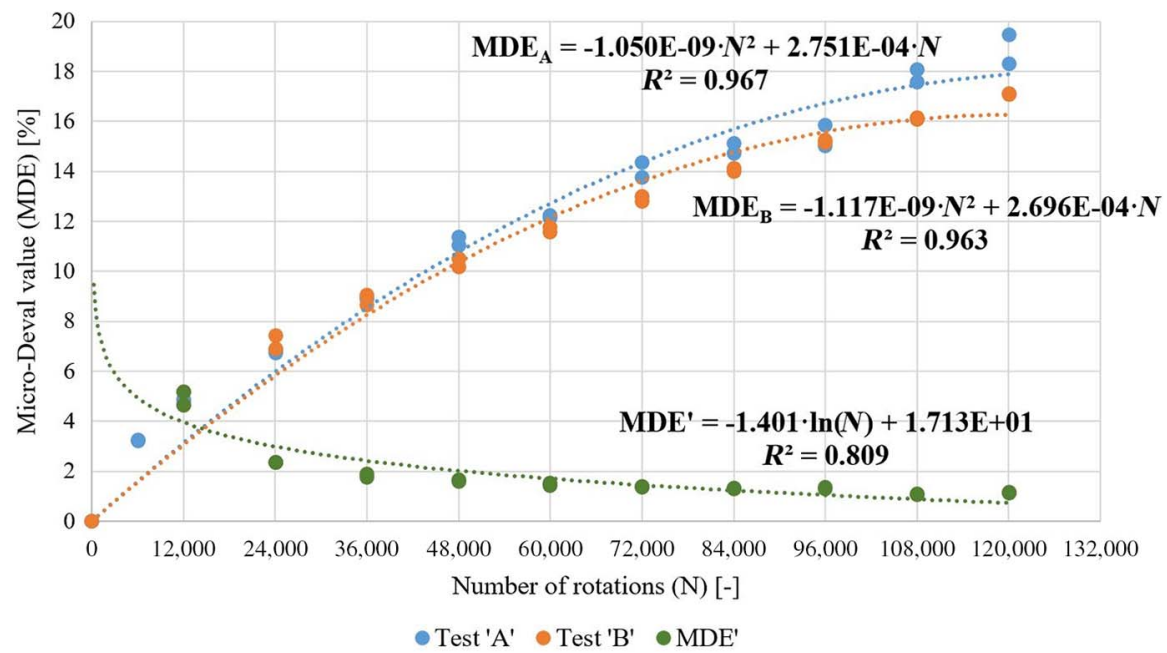

Fig. 5

Long-term Micro-Deval test results of the andesite from Recsk

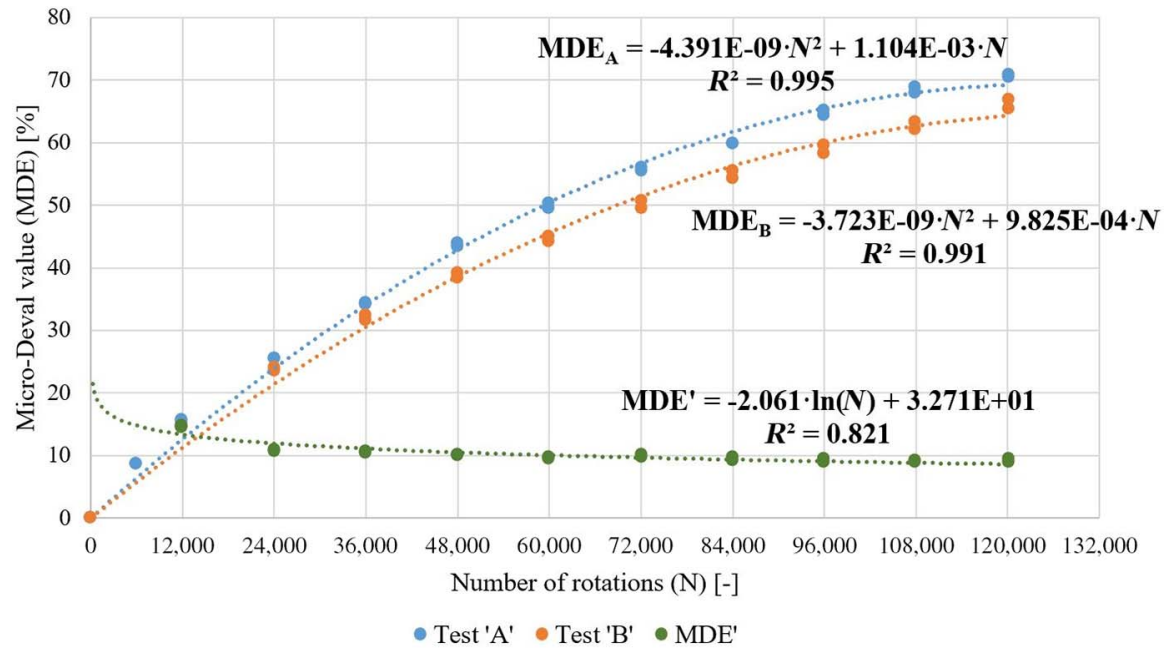

Fig. 6

Long-term Micro-Deval test results of the andesite from Nógrádkövesd

number of rotations, the decrease of the $M D E^{\prime}$ values was unambiguous and the quadratic model would show an increasing tendency after the minimum of the function. Applying logarithmic models provides better fit (Figs 5 and 6). 
Table 3

The $R^{2}$ values of the different models

\begin{tabular}{lcccccc}
\hline & \multicolumn{3}{c}{ Recsk } & \multicolumn{3}{c}{ Nógrádkövesd } \\
\hline Mathematical models & $M D E_{A}$ & $M D E_{B}$ & $M D E^{\prime}$ & $M D E_{A}$ & $M D E_{B}$ & $M D E^{\prime}$ \\
\hline Linear $(P=1)$ & 0.859 & 0.771 & 0.553 & 0.883 & 0.867 & 0.587 \\
\hline$P=2$ & 0.967 & 0.963 & 0.807 & 0.995 & 0.991 & 0.803 \\
\hline$P=3$ & 0.988 & 0.990 & 0.931 & 0.999 & 0.998 & 0.894 \\
\hline$P=4$ & 0.990 & 0.997 & 0.978 & 0.999 & 0.999 & 0.952 \\
\hline$P=5$ & 0.992 & 0.998 & 0.987 & 0.999 & 0.999 & 0.963 \\
\hline$P=6$ & 0.996 & 0.999 & 0.993 & 1.000 & 0.999 & 0.970 \\
\hline Logarithmic & - & - & 0.809 & - & - & 0.821 \\
\hline
\end{tabular}

$M D E_{A}$ : test result of test ' $A$ '; $M D E_{B}$ : test result of test ' $B$ '; $M D E^{\prime}$ ': modified Micro-Deval value; $P$ : the degree of the polynomial

Different mathematical models were used to find suitable curves which fit well to the measured data points. Linear and polynomial (the degree of the applied polynomials was increased to 6) curves were also analyzed. In the case of the modified Micro-Deval coefficient, the fitting of logarithmic curves was also tested. The Pearson's coefficients of linear, polynomial, and logarithmic correlations were calculated (Table 3). Although the polynomial models with higher degree provided the best $R^{2}$ values for the $M D E_{A}$ and $M D E_{B}$, it is suggested to use the easier quadratic models since these also provided adequate fitting to the data points to describe the behavior of the aggregates under continuous abrasive impact. Another issue in this question is that the curves of the higher polynomials show both increasing and decreasing trends in the studied range of the number of rotations, which makes these ambiguous.

\section{Conclusions}

The relevant guidelines and regulations of road construction or railway construction required the use of materials with relevant Micro-Deval coefficients (tested at 12,000 rotations). This study shows that this short-term test cannot describe the longterm behavior of the aggregates in the course of continuous abrasive impact. Thus, long-term durability tests are needed. This is especially important since aggregates used in road or railway construction are subjected to continuous abrasive impact. The Micro-Deval test results showed that the andesite from Recsk has a higher resistance against abrasive impacts $\left(M_{D E}=4.9\right)$ than the andesite from Nógrádkövesd 
$\left(M_{D E}=15.6\right)$, but these mere values of 12,000 rotations are far better than the ones obtained after 120,000 rotations. New parameters were introduced to describe the long-term properties of the aggregates. The long-term Micro-Deval coefficient (MDE) is calculated as the ratio of the abraded and the original mass after the increased number of rotations. The modified or relative Micro-Deval coefficient $\left(M D E^{\prime}\right)$ is determined as the degree of abrasion according to the measured masses at two sequential stages of the increasing number of rotations.

According to the long-term test results, the data points followed a decreasing trend. Quadratic models were suitable to describe the abrasion of the studied andesites. The newly introduced relative Micro-Deval coefficient could be described by logarithmic models.

The long-term properties could be analyzed by two test methods if the aggregate samples are washed, dried, and measured after every 12,000 rotations (test ' $\mathrm{B}$ ') or just at the end of the test process (test ' $A$ '). There were no significant differences between the results of these two test methods; the tendencies of the fitted curves were very similar. Only one pair of aggregate samples was needed for test 'B'; thus, a smaller amount of material is needed for this test, i.e., it is more economic.

\section{Acknowledgements}

The authors acknowledge the help of Gyula Emszt and Bálint Pálinkás in the laboratory tests. They are thankful to László Ézsiás and Colas Északkő Ltd. for providing andesite blocks for the laboratory tests.

\section{References}

Czinder, B., Á. Török 2015: Mátrából származó andezit kőanyagok kőzetfizikai és halmazszilárdsági vizsgálata [Analysis of rock mechanical properties and aggregate quality of andesite from Mátra Hill, Hungary]. - In: Török, Á., P. Görög, B. Vásárhelyi (Eds): Mérnökgeológia - Kőzetmechanika 2015 [Engineering Geology - Rock Mechanics 2015]. Hantken Kiadó, Budapest, Hungary, pp. 227-232. (in Hungarian).

Czinder, B., Á. Török 2017: Statistical analyses of strength parameters and aggregate properties of andesites from Hungary. - In: Hatvani, I.G., P. Tanos, M. Cvetković, F. Fedor (Eds): Proceedings Book of the 20th Congress of Hungarian Geomathematicians and 9th Congress of Croatian and Hungarian Geomathematicians "Geomathematics in multidisciplinary science - The new frontier?". Pécs Regional Committee of the Hungarian Academy of Sciences, Pécs, Hungary, pp. 124-131.

Đokić, O., V. Matović, S. Erić, K. Šarić 2015: Influence of engineering properties on Polished Stone Value (PSV): A case study on basic igneous rocks from Serbia. - Construction and Building Materials, 101, pp. 1088-1096.

Erichsen, E. 2015: Plotting aggregate degradation results from the Los Angeles test on a triangular diagram: Proposal of a new quality ranking for aggregates. - Bulletin of Engineering Geology and the Environment, 74, pp. 667-671.

Erichsen, E., A. Ulvik, K. Sævik 2011: Mechanical degradation of aggregate by the Los Angeles-, the Micro-Deval- and the Nordic test methods. - Rock Mechanics and Rock Engineering, 44, pp. 333-337. 
Gálos, M., L. Kárpáti 2007: Testing of Hungarian aggregates for railway ballast according to MSZ EN 13450: 2003. - Central European Geology, 50/4, pp. 353-361.

Gökceoğlu, C., R. Ulusay, H. Sönmez 2000: Factors affecting the durability of selected weak and claybearing rocks from Turkey, with particular emphases on the influence of the number of drying and wetting cycles. - Engineering Geology, 57, pp. 215-237.

Kahraman, S., O. Gunaydin 2007: Empirical methods to predict the abrasion resistance of rock aggregates. Bulletin of Engineering Geology and the Environment, 66, pp. 449-455.

Krutilová, K., R. Přikryl 2017: Relationship between polished stone value (PSV) and Nordic abrasion value (AN) of volcanic rocks. - Bulletin of Engineering Geology and the Environment, 76, pp. 85-99.

Liu, J., S. Zhao, A. Mullin 2017: Laboratory assessment of Alaska aggregates using Micro-Deval test. Frontiers of Structural and Civil Engineering, 11, pp. 27-34.

Miščević, P., G. Vlastelica 2011: Durability characterization of marls from the region of Dalmatia, Croatia. Geotechnical and Geological Engineering, 29, pp. 771-781.

Palassi, M., A. Danesh 2016: Relationships between abrasion/degradation of aggregate evaluated from various tests and the effect of saturation. - Rock Mechanics and Rock Engineering, 49, pp. 2937-2943.

Pang, L., S. Wu, J. Zhu, L. Wan 2010: Relationship between petrographical and physical properties of aggregates. - Journal of Wuhan University of Technology, Materials Science Edition, 25, pp. 678-681.

Prrikryl, R. 2001: Some microstructural aspects of strength variations in rocks. - International Journal of Rock Mechanics and Mining Sciences, 38, pp. 671-682.

Rigopoulos, I., B. Tsikouras, P. Pomonis, K. Hatzipanagiotou 2013: Determination of the interrelations between the engineering parameters of construction aggregates from ophiolite complexes of Greece using factor analysis. - Construction and Building Materials, 49, pp. 747-757.

Török, Á. 2007: Hungarian dimensional stones: An overview. - Zeitschrift der Deutschen Gesellschaft für Geowissenschaften, 158, pp. 361-374.

Török, Á. 2015: Los Angeles and Micro-Deval values of volcanic rocks and their use as aggregates, examples from Hungary. - In: Lollino, G., A. Manconi, F. Guzzetti, M. Culshaw, P. Bobrowsky, F. Luino (Eds): Engineering Geology for Society and Territory (Vol. 5, Urban Geology, Sustainable Planning and Landscape Exploitation). Springer International Publishing, Basel, Switzerland, pp. 115-118.

Török, Á., N. Rozgonyi, R. Přikryl, J. Přikrylová 2004: Leithakalk: The ornamental and building stone of Central Europe, an overview. - In: Přikryl, R. (Ed): Dimension Stone 2004: New Perspectives for a Traditional Building Material. Balkema Publishers, Rotterdam, the Netherlands, pp. 89-93.

Tugrul, A., I.H. Zarif 1999: Correlation of mineralogical and textural characteristics with engineering properties of selected granitic rocks from Turkey. - Engineering Geology, 51, pp. 303-317.

Ündül, Ö. 2016: Assessment of mineralogical and petrographic factors affecting petro-physical properties, strength and cracking processes of volcanic rocks. - Engineering Geology, 210, pp. 10-22.

Yilmaz, N.G., R.M. Goktan, Y. Kibici 2011: Relations between some quantitative petrographic characteristics and mechanical strength properties of granitic building stones. - International Journal of Rock Mechanics and Mining Sciences, 48, pp. 506-513.

Wang, D., H. Wang, Y. Bu, C. Schulze, M. Oeser 2015: Evaluation of aggregate resistance to wear with Micro-Deval test in combination with aggregate imaging techniques. - Wear, 338-339, pp. 288-296. 